\section{BMJ Open Respiratory Research}

\title{
The physiology of singing and implications for 'Singing for Lung Health' as a therapy for individuals with chronic obstructive pulmonary disease
}

\author{
Adam Lewis (D) , ${ }^{1}$ Keir Elmslie James Philip (DD , ${ }^{2}$ Adam Lound, ${ }^{3}$ Phoene Cave, ${ }^{1}$ \\ Juliet Russell, ${ }^{1}$ Nicholas S Hopkinson (D) ${ }^{2}$
}

\section{ABSTRACT}

Singing is an increasingly popular activity for people with chronic obstructive pulmonary disease (COPD). Research to date suggests that 'Singing for Lung Health' may improve various health measures, including health-related quality-of-life. Singing and breathing are closely linked processes affecting one another. In this narrative review, we explore the physiological rationale for 'Singing for Lung Health' as an intervention, focusing on the abnormalities of pulmonary mechanics seen in COPD and how these might be impacted by singing. The potential beneficial physiological mechanisms outlined here require further in-depth evaluation.

\section{INTRODUCTION}

Singing has become an increasingly popular approach for people with chronic respiratory disease and chronic obstructive pulmonary disease (COPD) in particular. ${ }^{1-3}$ Various types of singing are being used within groups, including those living with respiratory disease, from community choirs with minimal diseasespecific content adaptation to 'Singing for Lung Health' (SLH). 'SLH' incorporates breathing and vocal exercises comparable with those used by respiratory and speech and language therapists to support optimum breathing and vocalising. ${ }^{4-7}$ The British Lung Foundation has previously trained approximately 120 singing leaders to run 'SLH' groups, and prior to the COVID-19 pandemic, 65 groups were run by these leaders in the $\mathrm{UK}^{8}$ Rather than a focus on learning repertoire for performance, a typical SLH session would integrate physical and vocal warm-ups, breathing exercises, relaxation and carefully chosen vocal repertoire all to support breath control. The performance of these components has previously been evaluated, establishing intervention fidelity. ${ }^{9}$ In SLH, techniques aim to have physical benefits such as improving the use of respiratory and postural muscles, flexibility, reduced hyperinflation and improved breathing control. For example, participants extend sung phrases with appropriate repertoire and repeat-voiced fricatives performed with biofeedback techniques, which aim to synchronise breath and phonation and match the work of the primary muscles of respiration in a way that supports appropriate vocal effort. 'SLH' repertoire intends to have therapeutic impacts, which includes a variety of voice qualities, extended vocal ranges, aiming to improve vocal efficiency and contribute to breath management strategies. ${ }^{10}$ These techniques are delivered musically and creatively within the context of promoting full body movement.

'SLH' programmes are commonly run at least weekly for at least 6 weeks. There is some evidence to suggest that SLH may be clinically effective-improving quality of life and functional capacity for individuals with COPD. ${ }^{41-17}$ However, large-scale randomised controlled trial (RCT) data are lacking and the overall research quality in the field has been low to very low as judged by a Cochrane systematic review. ${ }^{11}$ Current SLH RCTs in progress are investigating SLH compared with standard care in people with COPD (NCT04034212, ISRCTN42943709) or comparing singing as the physical training intervention in pulmonary rehabilitation with the current gold-standard aerobic and strength exercise training in people with COPD (NCT03280355). Multiple systematic reviews have highlighted the need to increase the evidence base for singing, both in relation to clinical effectiveness and underlying physiological impacts related to participation. ${ }^{411}$ 
This narrative review was produced by a range of allied health and medical professionals, a singing group leader and vocal coach with a special interest in the field of SLH. The review explores the physiological rationale for SLH as an intervention in COPD, aiming to highlight potential physiological mechanisms requiring further research, focusing on:

1. The physiology of breathing and singing.

2. Abnormalities of pulmonary mechanics in COPD.

3. Potential physiological impact of singing in people with COPD.

We use the term 'may' both to raise potential interesting hypotheses for future research in SLH and where uncertainties in the literature remain due to a lack of quality evidence.

\section{THE PHYSIOLOGY OF BREATHING AND SINGING \\ Breathing control while singing}

During quiet breathing, inspiration is an active process engaging the muscles of respiration, while expiration is passive, driven largely by lung elastic recoil. During physical activity, as metabolic demands rise, minute ventilation increases by increasing both tidal volume and respiratory rate. This requires increased flow rates and the recruitment of abdominal muscles to deliver active expiration. Regulation of the glottic aperture by laryngeal muscle activity also helps to control ventilation. ${ }^{18}$ The glottis widens on inspiration and narrows on expiration. ${ }^{19}$ Glottic opening occurs prior to the descent of the diaphragm on inspiration, and the glottis acts as a valve to influence the expiratory time of the respiratory cycle. ${ }^{20}$ Therefore, the larynx could be considered a key modulator of expiratory flow. ${ }^{20}$

During speech and singing, breath duration and flow rates are controlled to support sound generation by the larynx. Thus, inspiration and expiration are both active in order to adjust lung volumes for phrase length and sound volume. ${ }^{21}$ Herbst ${ }^{10}$ critiqued the traditional linear relationship of the power-source-filter model, where the sung voice is determined by the lungs and then modified by the larynx and vocal tract. Rather he states that each system and vocal subsystem has a physical effect on the other. In this regard, changes in vocal function will alter exhalation accordingly. Singers partly control exhalation through the activity of the abdominal muscles including the rectus abdominus, internal and external obliques and transverse abdominus. ${ }^{21}$ The internal intercostals also work to draw the ribcage during phonation. ${ }^{21}$ During speech, inspiratory time is reduced and expiratory time is lengthened (compared with a passive breathing cycle). ${ }^{22}$ Subglottic pressure is regulated more actively during speech and singing compared with unphonated breathing and even more so while singing. ${ }^{23-25}$

Phonation requires sustaining-controlled exhalation. In a study using electrical impedance tomography, Traser et $a l^{26}$ show that phonation modulates expiratory airflow in a more uniform pattern compared with unphonated breathing as phonation prevents the majority of air being exhaled at the start of the breath. Zhang ${ }^{23}$ reports that subglottal pressures can be maintained throughout exhalation with minimal glottal resistance. This results in the lung volume at the end of the phrase being close to the residual volume. This requires higher expiratory pressures following inspiratory pressures to change lung volumes at this point in lung capacity. The respiratory and vocal mechanisms work synergistically to optimise efficiency in the work of singing.

\section{Lung function parameters in singers}

Total lung capacity depends on the balance between inspiratory muscle strength and the elastic recoil of the respiratory system as well as the individual's size, sex, ethnicity and disease state. Respiratory muscle strength can be improved with specific training ${ }^{2728}$ or as a result of pulmonary rehabilitation. ${ }^{29}$ Watson $e t a p^{30}$ studied professional singers comparing singing and non-singing ventilatory tasks. The study found that vocalisation required activation of additional muscles, such as latissimus dorsi, compared with non-singing ventilatory tasks, which may be relevant in relation to respiratory muscle strength. Furthermore, singers have been shown to have forced expiratory volumes and vital capacities greater than population norms. ${ }^{31-34}$ Differences in lung function parameters between singers and non-singers likely result from multiple factors, including duration of singing participation $^{33}$; a propensity for people with pre-existing above-average respiratory function to become singers as is known from other physically demanding professions; and, potentially, lifestyle choices including smoking less and exercising more compared with peers. ${ }^{34}$ However, it is speculated that repeated focus on controlled exhaled breath improves expiratory muscle strength. ${ }^{32}$

A small study of nine professional singers showed that they were able to dynamically alter vocal fold aperture and abdominal volumes to control their breath. ${ }^{35}$ Furthermore, a small study comparing seven classically trained singers to four untrained individuals suggested singers were able to substantially alter the coordination of abdominal and thoracic volume change during singing compared with quiet breathing, by using a greater percentage of abdominal contribution to lung volume change. ${ }^{36}$ Solomini $e t a l^{36}$ comment that classically trained singers increase abdominal pressures to enable a more effective expiration by optimising muscular lengthtension ratios and force-generation capacity. It is speculated that this is possible because during singing, the anterior diaphragm and ribcage, and the middle and posterior diaphragm and ribcage, act as different functional units. These separate units maintain subglottal pressures with changing recoil forces on expiration. ${ }^{37}$

During singing, abdominal muscle activity increases. Macdonald $e t a l^{8}$ investigated the acute effects of singing on abdominal musculature in 25 healthy adults using ultrasound. During singing, the internal oblique and 
transverse abdominis (TA) muscles both contract and TA has a greater percentage contraction compared with baseline conditions at a comfortable inspiration. Salomoni et $a l^{36}$ used respiratory inductance plethysmography bands, showing that trained singers use a greater abdominal contribution to change lung volumes during singing compared with untrained controls. It is important to recognise that the majority of singing studies have been conducted on classically trained singers, whose breathing requirements are specific to the style that they sing, and different to contemporary pop or global repertoire, often used in SLH.

\section{ABNORMALITIES IN PULLMONARY MECHANICS IN COPD}

COPD encompasses pathologies including chronic bronchitis and emphysema, which alter pulmonary mechanics. ${ }^{39}$ Airflow obstruction occurs results from loss of small airways, airway inflammation and wall thickening, mucous hypersecretion, an impaired mucociliary escalator and airway muscle hypertrophy. Additionally, emphysema reduces lung elastic recoil, promoting premature airway closure and gas trapping. The combination of increased airflow resistance and increased lung compliance increases the time constant of lung units and leads to hyperinflation, which worsens with exercise. ${ }^{4041}$ As operating lung volumes increase, the inspiratory muscles develop a mechanical disadvantage with a reduced force generation capacity because of the lengthtension relationship as the diaphragm has a shorter, flatter position. ${ }^{42}{ }^{43}$ Inspiratory reserve volume decreases as total lung capacity is approached and the flatter position on the pressure-volume relationship means that the work of inspiration increases. This leads to mechanical constraint on maximum ventilation, recruitment of accessory muscles of respiration, breathlessness and the premature termination of exercise. In addition, skeletal muscle weakness and loss of endurance are common and increase ventilatory demand during daily activities. ${ }^{44-46}$ Forty seven per cent of patients with COPD have been shown to have dysfunctional breathing, which is more severe and prevalent than in asthmatics or healthy controls. ${ }^{47}$ Furthermore, the Nijmegen Questionnaire score, a measure of hyperventilation syndrome (a type of dysfunctional breathing), is a strong independent determinant of disease-related quality of life in COPD as measured by the COPD Assessment Test. ${ }^{48}$ Both the Nijmegen Questionnaire and COPD Assessment Test measure shortness of breath and chest tightness, and to the authors' knowledge, divergent validity between these measures has yet to be established, which is a potential limitation to Brien et al s study. ${ }^{48}$ Nevertheless, the findings from both Law et $a l^{47}$ and Brien et $a l^{48}$ indicate that breathing pattern retraining is indicated in COPD populations. Breathing pattern retraining has shown to improve physiological outcomes for individuals with COPD, including improvements in functional exercise capacity, respiratory pattern, respiratory rate, lung function, oxygenation, a reduction in dynamic hyperinflation on exertion and functional anatomical dead space volume. ${ }^{49-55}$

\section{POTENTIAL PHYSIOLOGICAL IMPACT OF SINGING IN PEOPLE WITH COPD}

There is a clear physiological link between the upper airway and lower airway, ventilation and voice quality. ${ }^{10}$ It has been stated that dysphonia in COPD can be functional in origin and, therefore, corrected somewhat with therapy. ${ }^{56}$

Techniques that slow down expiration allow a greater degree of lung emptying, which in turn lowers operating lung volumes and can make breathing more comfortable for individuals living with COPD.$^{57}$ Many breathing retraining techniques focus on slowing down exhalation. Singing activities can be adapted and performed in a similar fashion. In addition, singing may strengthen musculature, improve posture and work as an exercise modality as a structured, repetitive and goal-directed activity, all with potential impacts on symptoms. We explore such possibilities below.

Singing was first documented as a potential therapeutic intervention for individuals with COPD 35 years ago, ${ }^{58}$ where it was suggested that singing enabled greater expectoration of sputum and improved blood gasses when the patients took larger breaths to sing. Goldenberg $^{59}$ has previously discussed how the increase in airway shear forces and oscillatory action of singing may help expectorate sputum. A further potential therapeutic mechanism is the alteration of breathing patterns for people living with COPD, which has potential clinical utility. ${ }^{50}$ Binazzi et a $l^{60}$ investigated the breathing pattern of people with COPD singing a Christmas carol using optoelectric plethysmography. None of the participants in the study had professional or amateur singing experience. Individuals listened to the Italian version of ' $\mathrm{O}$ Christmas Tree' once before performing all four verses three times-the third attempt used for analysis. The authors report singers adopted higher operating volumes to maintain adequate expiratory flow generation. Female singers showed greater volume changes in their chest wall, whereas male singers sung with greater abdomen volume changes compared with quiet breathing. In this study, singing altered breathing patterns in patients with COPD and there was wide variability in measured end expiratory chest wall volumes between individuals from a small sample size. It is not known whether the different volume changes between sexes was driven by different body shapes or different keys and registers used in singing the chosen repertoire.

Given that singing requires participants to consciously modulate their breathing patterns, it is plausible that appropriately selected singing repertoire and vocalisation tasks could be used to enable breathing pattern optimisation. Lord et al studied weekly 'SLH' training for ${ }^{12} 6$ and 8 weeks. ${ }^{13}$ Primary outcome measures relating to breath control ${ }^{12}$ and physical activity ${ }^{13}$ were not met. 
Though of note, the breath control measures were developed to assess hyperventilation rather than breathing control in COPD; therefore, their value in this context is questionable. However, concerning secondary outcome measures, both studies identified improvements in the physical component score of the SF-36 health status assessment tool. As discussed previously, improving respiratory strength could be useful for people with COPD, and inspiratory muscle strength has been shown to improve with singing for a group of older people, of whom a quarter were living with 'respiratory disease'. ${ }^{61}$ However, further research including individuals diagnosed with COPD is warranted.

An RCT in Brazil, comparing 24 group singing sessions to 24 handcraft work sessions for people with $\mathrm{COPD},{ }^{62}$ suggested singing group participants experienced reduced dyspnoea and improved oxygen saturations during singing. However, these changes did not appear to be sustained beyond the end of the 24-week programme.

The perception of severity of breathlessness does not always match the degree of airway pathophysiology in COPD. ${ }^{63}$ Herigstad et $a l^{64}$ demonstrated significant correlations between improvements in how breathless and anxious patients felt following a course of pulmonary rehabilitation and the brain activity of multiple regions according to functional MRI, suggesting a potential role for modifications to interoception. They suggest that becoming breathless in a safe space under supervision may alter the perceptions of breathlessness. Approaches, such as SLH, focus on creating safe, supervised spaces, which may help to explain changes in breathlessness reported by SLH participants. The moderate physical activity of SLH is not only enjoyable, but one where the breath is used to create sound in music collaboratively within a group. The result of such activity can be profound: 'When we sing, the breath enables creation of something new, promoting life not inhibiting it. It is the barrier that is forgotten, not the breath' ${ }^{8}$

Posture and the voice are coordinated during vocal effort, particularly with the correlation of forward sagittal movement of the trunk at increased sound pressure levels. ${ }^{65}$ The ability for the diaphragm to act as a postural control muscle within the trunk is reduced in situations where individuals have increased neural respiratory drive, dead space ventilation and simultaneous arm movements. ${ }^{66}$ Evidence suggests that singing challenges postural control and singing training improves postural control. ${ }^{67}$ In the study by Peultier-Celli et al, ${ }^{67}$ professionally trained singers challenged their balance by standing on a force plate in various conditions, including eyesopen, eyes-closed and singing chosen arias. Singers' sway was greater when singing compared with standing with eyes open. However, better postural control was observed in those who had more years of singing experience. 'SLH' actively trains postural control to support singing. One of the 10 main competencies suggested for trained singing leaders is that they have 'a holistic understanding of the kinaesthetics and whole body proprioception in breathing. ${ }^{9}$ It is not yet certain how SLH affects posture, but qualitative reports indicate that posture improves through participation ${ }^{12}$ with pilot quantitative data, suggesting improvements to balance confidence. ${ }^{68}$

'SLH' exercises have been compared with different speeds of treadmill walking in a small study in healthy individuals showing that singing is associated with a similar metabolic demand to moderately vigorous physical activity. ${ }^{69}$ This study also demonstrated that tidal volumes during singing were greater than those performed for treadmill walking matched for physical activity intensity (Mean Difference: $1.18 \mathrm{~L} \mathrm{p}=0.01$ ), which is likely to relate to the additional volume of air needed for phonation in addition to metabolic requirements, and the phrasing of singing components which necessitated reduced breathing frequency compared with what might have been taken naturally. Further research is required to see if this is reproduced in older people and in people with COPD.

Liuzijue Qigong is a form of traditional Chinese martial art characterised by breathing, which focuses on the use of the primary muscles of respiration (diaphragmatic breathing), pursed-lip breathing and the production of different sounds during limb movements. ${ }^{70}$ The physical and vocal warm-up exercises of 'SLH' are similar exercises to Liuzijue Qigong. Liuzijue Qigong has been shown to improve maximal inspiratory and expiratory pressures and specific airway conductance in patients with COPD. ${ }^{70-72}$ The sounds produced in Liuzijue Qigong are similar to the voiced fricatives used as vocal warm-ups in SLH. Similar to Liuzijue Qigong, many repertoire choices in SLH include long phrases with open vowel sounds. Long phrases and open vowel sounds have been beneficial in reducing respiratory rate and increased heart rate variability via toning and repeated mantra singing. ${ }^{73-75}$ Further research is needed to determine the physiological sustained effects once the singing stops. 'SLH' exercises also focus on semiocclusion for extended breaths, which also aim to control and support exhalation. 'SLH' leaders receive vocal training and toolkits prior to running groups. It is the skill of the trained singing leader to use the wide-ranging researchbased techniques sensitively, within the flow of musical activity to engage individuals, making the experience fun and offer a perceived non-clinical environment, which promotes self-expression. The weekly repetition of exercises and games aim to reinforce the ability to use these techniques independently as self-management strategies.

Table 1 details the actions of singing and the potential mechanisms of benefit for individuals with COPD:

Table 1 highlights potential physiological benefits of singing for individuals with COPD. However, due to both the lack of high-quality evidence and relatively few studies specific to singing training which is not classically derived or studies specific to SLH, more definitive associations and causality statements cannot currently be made between physiological studies in COPD, singing and the practice of SLH. The findings from small 
Table 1 Singing actions and proposed/potential physiological basis of benefits for individuals with COPD

\section{Singing action}

Expiration during singing requires controlled muscle activity

Regulation of glottic aperture and improved glottic efficiency

Alters abdominal and thoracic contribution to lung volume changes.

Inspiratory muscle training

Enhancing airway shear forces

Training of posture and balance

Singing is a moderately intense physical activity (shown specifically with core components of SLH)

\section{Proposed benefits for individuals with COPD}

Controlling expiratory flow, ${ }^{2037}$ lower operating lung volumes and make breathing more comfortable.

Controlling of expiratory flow. ${ }^{20}$

Doming the diaphragm supports exhalation, also improving lengthtension ratio and force-generation capacity on inspiration. ${ }^{36} 37$

Greater inspiratory strength is required to generate higher pressures to inspire at large lung volumes (hyperinflation). ${ }^{78}$ Facilitates active phases of breathing, when required.

Potential to promote airway clearance, reduces symptom burden ${ }^{59}$

Optimises lung function, potential to reduce risk of falls and increase balance confidence ${ }^{68}$

Increasing physical activity levels ${ }^{69}$ in a population significantly physically inactive ${ }^{79}$

COPD, chronic obstructive pulmonary disease; SLH, Singing for Lung Health.

studies in classically trained singers to date have limited external validity compared with the breath management required from different repertoire and training, such as pop singing, where singers move from speech, to belttype singing and falsetto. The breath demands will vary accordingly. Herbst ${ }^{10}$ provides a good review of how different voice subsystems contribute to breath support, which we do not cover in this review.

Recommendations from previous systematic reviews remain, ${ }^{411}$ where more research is required in order to establish the clinical effectiveness and physiological mechanisms underpinning any beneficial effects achieved through SLH participation. Table 2 provides some research questions and types of clinical studies which are now required in order to further explore the physiological mechanisms of potential benefit and clinical effectiveness of SLH:

This review is specifically focused on physiological rationale and outcomes. However, we acknowledge that SLH is an intervention, which aims to provide holistic

Table 2 Physiological research questions and proposed clinical effectiveness studies required in SLH

\section{Physiological research questions}

Do SLH techniques and participation in SLH groups change sputum expectoration volume, cough and exacerbation frequency?

How do different SLH techniques change laryngeal function SLH group participation as a maintenance intervention post-PR and airflow compared with passive breathing?

How do SLH techniques change respiratory and abdominal muscle activity compared with passive breathing?

How do SLH techniques change thoracoabdominal volumes compared with passive breathing?

How does participation in SLH groups change posture and balance?

Does long term participation in SLH groups alter the trajectory of lung function decline in COPD?

What level of physical activity is performed by individuals in SLH vs usual care in different settings and populations.

a SLH group?

Does participation in SLH groups improve inspiratory and expiratory muscle strength?

Is there a difference in breathing pattern between SLH repertoire directed performance and other repertoire such as pop and classical?

\section{Clinical effectiveness studies}

SLH group participation vs generic community choir participation. completion vs standard care.

SLH as one-to-one inpatient and outpatient option vs traditional physiotherapy for symptom management (breathlessness, airway clearance).

Online SLH group participation vs face-to-face group participation.

Post-exacerbation SLH vs standard care.

PR vs SLH for those who decline PR.

COPD, chronic obstructive pulmonary disease; PR, pulmonary rehabilitation; SLH, Singing for Lung Health. 
health benefit. Any health-related benefits, resulting from participation, are likely multifactorial with psychological and social components, which are known to be important in COPD. ${ }^{12} 16687677$ Further research should continue to use a range of biopsychosocial outcomes in order to evaluate the different mechanisms of benefit effectively.

\section{CONCLUSION}

Breathing and singing are intimately related. There is a good theoretical rationale to support the therapeutic use of singing for people with COPD as a method of improving physiological parameters and breath control; however, the research in this area is limited and of generally low quality. Further research is required to more effectively assess the impact of SLH for people with COPD, and which physiological mechanisms underlie any improvements observed.

Acknowledgements AL would like to thank Dr Mandy Jones and Professor Joy Conway for their support during this work.

Contributors AL prepared the first draft of the manuscript. All other authors contributed to revisions and reviewed the final version.

Funding The authors have not declared a specific grant for this research from any funding agency in the public, commercial or not-for-profit sectors.

Competing interests $\mathrm{AL}, \mathrm{PC}$ and JR train singing leaders to run Singing for Lung Health groups specifically for individuals living with respiratory disease.

Patient consent for publication Not applicable.

Provenance and peer review Not commissioned; externally peer reviewed.

Data availability statement No data are available. Not applicable.

Open access This is an open access article distributed in accordance with the Creative Commons Attribution 4.0 Unported (CC BY 4.0) license, which permits others to copy, redistribute, remix, transform and build upon this work for any purpose, provided the original work is properly cited, a link to the licence is given, and indication of whether changes were made. See: https://creativecommons.org/ licenses/by/4.0/.

ORCID iDs

Adam Lewis http://orcid.org/0000-0002-0576-8823

Keir Elmslie James Philip http://orcid.org/0000-0001-9614-3580

Nicholas S Hopkinson http://orcid.org/0000-0003-3235-0454

\section{REFERENCES}

1 Philip K, Lewis A, Hopkinson NS. Music and dance in chronic lung disease. Breathe 2019;15:116-20.

2 Philip KE, Cartwright LL, Westlake D, et al. Music and dance in respiratory disease management in Uganda: a qualitative study of patient and healthcare professional perspectives. BMJ Open 2021;11:2021.04.27.21255985

3 Downes C, Philip KEJ, Lewis A, et al. Singing for breathing Uganda: group singing for people with chronic lung disease in Kampala. $J$ Appl Arts Health 2019;10:219-28.

4 Lewis A, Cave P, Stern M, et al. Singing for lung Health-a systematic review of the literature and consensus statement. NPJ Prim Care Respir Med 2016;26:16080.

5 Kaasgaard M, Andersen IC, Rasmussen DB, et al. Heterogeneity in Danish lung choirs and their singing leaders: delivery, approach, and experiences: a survey-based study. BMJ Open 2020;10:e041700.

6 Bott J, Blumenthal S, Buxton M, et al. Guidelines for the physiotherapy management of the adult, medical, spontaneously breathing patient. Thorax 2009;64 Suppl 1:i1-52.

7 Titze IR. Voice training and therapy with a semi-occluded vocal tract: rationale and scientific underpinnings. J Speech Lang Hear Res 2006;49:448-59.

8 Cave P, Lewis A, Fancourt D. Singing for Lung Health. In: Heydon $\mathrm{R}$, Fancourt D, Cohen AJ, eds. The Routledge companion to
Interdiciplinary studies in singing, volume III: wellbeing. New York Routledge, 2020.

9 Lewis A, Cave P, Hopkinson NS. Singing for lung health: a qualitative assessment of a British lung Foundation programme for group leaders. BMJ Open Respir Res 2017;4:e000216.

10 Herbst CT. A Review of Singing Voice Subsystem InteractionsToward an Extended Physiological Model of "Support". J Voice 2017:31:249.e13-249.e19.

11 McNamara R, Epsley C, Coren E. Singing for adults with chronic obstructive pulmonary disease (COPD). Cochrane Database of Systematic Reviews 2017;12:CD012296.

12 Lord VM, Cave P, Hume VJ, et al. Singing teaching as a therapy for chronic respiratory disease--a randomised controlled trial and qualitative evaluation. BMC Pulm Med 2010;10:41.

13 Lord VM, Hume VJ, Kelly JL, et al. Singing classes for chronic obstructive pulmonary disease: a randomized controlled trial. BMC Pulm Med 2012;12:69.

14 Clift S, Skingley A, Page S, et al. Singing for better breathing: findings from the Lambeth and Southwark singing and COPD project. Kent, England: Sidney De Haan Research Centre for Arts and Health, 2017.

15 Parshall MB, Schwartzstein RM, Adams L, et al. An official American thoracic Society statement: update on the mechanisms, assessment, and management of dyspnea. Am J Respir Crit Care Med 2012;185:435-52.

16 McNaughton A, Weatherall M, Williams M, et al. Sing your lungs Out-a community singing group for chronic obstructive pulmonary disease: a 1-year pilot study. BMJ Open 2017;7:e014151.

17 Lewis A, Cave P, Hopkinson NS. Singing for lung health: service evaluation of the British lung Foundation programme. Perspect Public Health 2018;138:215-22.

18 Kuna ST, Insalaco G, Villeponteaux DR, et al. Effect of hypercapnia and hypoxia on arytenoideus muscle activity in normal adult humans. J Appl Physiol 1993;75:1781-9.

19 Brancatisano T, Collett PW, Engel LA. Respiratory movements of the vocal cords. J Appl Physiol Respir Environ Exerc Physiol 1983;54:1269-76.

20 Sasaki CT, Weaver EM. Physiology of the larynx. Am J Med 1997;103:9S-18.

21 Watson AH. Breathing in Singing. In: Welsh GF, Howard DM, Nix J, eds. The Oxford Handbook of singing. Oxford: Oxford University Press, 2014.

22 Lee L, Loudon RG, Jacobson BH, et al. Speech breathing in patients with lung disease. Am Rev Respir Dis 1993;147:1199-206.

23 Zhang Z. Respiratory laryngeal coordination in airflow conservation and reduction of respiratory effort of phonation. $J$ Voice 2016;30:760.e7-760.e13.

24 Thomasson M, Sundberg J. Consistency of phonatory breathing patterns in professional operatic singers. J Voice 1999;13:529-41.

25 Ravi SK, Shabnam S, George KS, et al. Acoustic and aerodynamic characteristics of Choral singers. J Voice 2019;33:803.e1-803.e5.

26 Traser L, Knab J, Echternach M, et al. Regional ventilation during phonation in professional male and female singers. Respir Physiol Neurobiol 2017;239:26-33.

27 Langer D, Ciavaglia C, Faisal A, et al. Inspiratory muscle training reduces diaphragm activation and dyspnea during exercise in COPD. J Appl Physiol 2018;125:381-92.

28 Daynes E, Greening NJ, Harvey-Dunstan TC, et al. High-Frequency airway oscillating device for respiratory muscle training in subjects with COPD. Respir Care 2018;63:584-90.

29 Lee EN, Kim MJ. Meta-Analysis of the effect of a pulmonary rehabilitation program on respiratory muscle strength in patients with chronic obstructive pulmonary disease. Asian Nurs Res 2019:13:1-10.

30 Watson AHD, Williams C, James BV. Activity patterns in latissimus dorsi and sternocleidomastoid in classical singers. $J$ Voice 2012;26:e95-105.

31 Carroll LM, Sataloff RT, Heuer RJ, et al. Respiratory and glottal efficiency measures in normal classically trained singers. $J$ Voice 1996;10:139-45.

32 Irzaldy A, Wiyasihati SI, Purwanto B. Lung vital capacity of Choir singers and Nonsingers: a comparative study. $J$ Voice 2016:30:717-20.

33 Roy AS, Bandyopadhyay A. Pulmonary function studies in female singers of Kolkata, India. J Hum Ergol 2015;44:75-81.

34 Schorr-Lesnick B, Teirstein AS, Brown LK, et al. Pulmonary function in singers and wind-instrument players. Chest 1985;88:201-5.

35 Lam Tang JA, Boliek CA, Rieger JM. Laryngeal and respiratory behavior during pitch change in professional singers. $J$ Voice 2008;22:622-33. 
36 Salomoni S, van den Hoorn W, Hodges P. Breathing and singing: objective characterization of breathing patterns in classical singers. PLoS One 2016;11:e0155084.

37 Traser L, Özen AC, Burk F, et al. Respiratory dynamics in phonation and breathing-A real-time MRI study. Respir Physiol Neurobiol 2017;236:69-77.

38 Macdonald I, Rubin JS, Blake E, et al. An investigation of abdominal muscle recruitment for sustained phonation in 25 healthy singers. $J$ Voice 2012;26:815.e9-815.e16.

39 Hopkinson NS, Molyneux A, Pink J, et al. Chronic obstructive pulmonary disease: diagnosis and management: summary of updated NICE guidance. BMJ 2019;366:I4486.

40 O'Donnell DE, Parker CM. COPD exacerbations . 3: Pathophysiology. Thorax 2006:61:354-61.

41 Neder JA, Berton DC, Müller PdeT, et al. Ventilatory inefficiency and exertional dyspnea in early chronic obstructive pulmonary disease. Ann Am Thorac Soc 2017;14:S22-9.

42 Moore AJ, Soler RS, Cetti EJ, et al. Sniff nasal inspiratory pressure versus IC/TLC ratio as predictors of mortality in COPD. Respir Med 2010;104:1319-25.

43 Moore AJ, Stubbings A, Swallow EB, et al. Passive properties of the diaphragm in COPD. J Appl Physiol 2006;101:1400-5.

44 Shrikrishna D, Patel M, Tanner RJ, et al. Quadriceps wasting and physical inactivity in patients with COPD. Eur Respir $J$ 2012;40:1115-22.

45 Maddocks M, Shrikrishna D, Vitoriano S, et al. Skeletal muscle adiposity is associated with physical activity, exercise capacity and fibre shift in COPD. Eur Respir J 2014;44:1188-98.

46 Jackson AS, Shrikrishna D, Kelly JL, et al. Vitamin D and skeletal muscle strength and endurance in COPD. Eur Respir $J$ 2013;41:309-16.

47 Law N, Ruane LE, Low K, et al. Dysfunctional breathing is more frequent in chronic obstructive pulmonary disease than in asthma and in health. Respir Physiol Neurobiol 2018;247:20-3.

48 Brien SB, Stuart B, Dickens AP, et al. Independent determinants of disease-related quality of life in COPD - scope for nonpharmacologic interventions? Int J Chron Obstruct Pulmon Dis 2018;13:247-56.

49 Pomidori L, Campigotto F, Amatya TM, et al. Efficacy and tolerability of yoga breathing in patients with chronic obstructive pulmonary disease: a pilot study. J Cardiopulm Rehabil Prev 2009;29:133-7.

50 Estève F, Blanc-Gras N, Gallego J, Benchetrit G, et al. The effects of breathing pattern training on ventilatory function in patients with COPD. Biofeedback Self Regul 1996;21:311-21.

51 Sulemanji DS, Bao F, Jiang Y, et al. A unidirectional breathing pattern improves breathing efficiency in subjects with severe COPD. Respir Care 2014;59:1487-93.

52 Ubolnuar N, Tantisuwat A, Thaveeratitham P, et al. Effects of breathing exercises in patients with chronic obstructive pulmonary disease: systematic review and meta-analysis. Ann Rehabil Med 2019;43:509-23.

53 Collins EG, Langbein WE, Fehr L, et al. Can ventilation-feedback training augment exercise tolerance in patients with chronic obstructive pulmonary disease? Am J Respir Crit Care Med 2008; $177: 844-52$

54 Holland AE, Hill CJ, Jones AY, et al. Breathing exercises for chronic obstructive pulmonary disease. Cochrane Database Syst Rev 2012;10:Cd008250.

55 Yang Y, Wei L, Wang S, et al. The effects of pursed lip breathing combined with diaphragmatic breathing on pulmonary function and exercise capacity in patients with COPD: a systematic review and meta-analysis. Physiother Theory Pract 2020:1-11.

56 Hassan MM, Hussein MT, Emam AM, et al. Is insufficient pulmonary air support the cause of dysphonia in chronic obstructive pulmonary disease? Auris Nasus Larynx 2018;45:807-14.

57 Borge CR, Hagen KB, Mengshoel AM, et al. Effects of controlled breathing exercises and respiratory muscle training in people with chronic obstructive pulmonary disease: results from evaluating the quality of evidence in systematic reviews. BMC Pulm Med 2014;14:184.

58 Bolger EP, Judson MA. The therapeutic value of singing. N Engl J Med 1984;311:311.

59 Goldenberg RB. Singing lessons for respiratory health: a literature review. J Voice 2018;32:85-94.

60 Binazzi B, Lanini B, Gigliotti F, et al. Breathing pattern and chest wall kinematics during phonation in chronic obstructive pulmonary disease patients. Respiration 2013;86:462-71.

61 Fu MC, Belza B, Nguyen H, et al. Impact of group-singing on older adult health in senior living communities: a pilot study. Arch Gerontol Geriatr 2018;76:138-46.

62 Bonilha AG, Onofre F, Vieira ML, et al. Effects of singing classes on pulmonary function and quality of life of COPD patients. Int $J$ Chron Obstruct Pulmon Dis 2009;4:1-8.

63 Müllerová H, Lu C, Li H, et al. Prevalence and burden of breathlessness in patients with chronic obstructive pulmonary disease managed in primary care. PLoS One 2014;9:e85540.

64 Herigstad M, Faull OK, Hayen A, et al. Treating breathlessness via the brain: changes in brain activity over a course of pulmonary rehabilitation. Eur Respir J 2017;50. doi:10.1183/13993003.010292017. [Epub ahead of print: 1209 2017].

65 Lagier A, Vaugoyeau M, Ghio A, et al. Coordination between posture and phonation in vocal effort behavior. Folia Phoniatr Logop 2010;62:195-202.

66 Hodges PW, Heijnen I, Gandevia SC. Postural activity of the diaphragm is reduced in humans when respiratory demand increases. J Physiol 2001;537:999-1008.

67 Peultier-Celli L, Audouin M, Beyaert C, et al. Postural control in Lyric singers. J Voice 2020. doi:10.1016/j.jvoice.2020.04.019. [Epub ahead of print: 23 May 2020].

68 Philip KE, Lewis A, Jeffery E, et al. Moving singing for lung health online in response to COVID-19: experience from a randomised controlled trial. BMJ Open Respir Res 2020;7:e000737.

69 Philip KE, Lewis A, Buttery SC, et al. Physiological demands of singing for lung health compared with treadmill walking. BMJ Open Respir Res 2021;8:e000959.

70 Xiao C-M, Zhuang Y-C. Efficacy of Liuzijue Qigong in individuals with chronic obstructive pulmonary disease in remission. J Am Geriatr Soc 2015;63:1420-5.

71 Wu W, Liu X, Liu J, et al. Effectiveness of water-based Liuzijue exercise on respiratory muscle strength and peripheral skeletal muscle function in patients with COPD. Int $J$ Chron Obstruct Pulmon Dis 2018;13:1713-26.

72 Li P, Liu J, Lu Y, et al. Effects of long-term home-based Liuzijue exercise combined with clinical guidance in elderly patients with chronic obstructive pulmonary disease. Clin Interv Aging 2018;13:1391-9.

73 Vickhoff B, Malmgren $\mathrm{H}$, Aström R, et al. Music structure determines heart rate variability of singers. Front Psychol 2013;4:334.

74 Ruiz-Blais S, Orini M, Chew E, eds. Long vocalisations entrain heart rate variability in non-expert singers. Movement and Music in Therapy. London, 2019.

75 Bernardi NF, Snow S, Peretz I, et al. Cardiorespiratory optimization during improvised singing and toning. Sci Rep 2017;7:8113.

76 Bu F, Philip K, Fancourt D. Social isolation and loneliness as risk factors for hospital admissions for respiratory disease among older adults. Thorax 2020;75:597-9.

77 Liu H, Song M, Zhai Z-H, et al. Group singing improves depression and life quality in patients with stable COPD: a randomized community-based trial in China. Qual Life Res 2019;28:725-35.

78 Loring SH, Garcia-Jacques M, Malhotra A. Pulmonary characteristics in COPD and mechanisms of increased work of breathing. J Appl Physiol 2009;107:309-14.

79 Vorrink SNW, Kort HSM, Troosters T, et al. Level of daily physical activity in individuals with COPD compared with healthy controls. Respir Res 2011;12:33. 